\title{
Notes on Transcription, Transliteration, and Naming Practices
}

ibetan terms are transcribed phonetically throughout this book.
The transcription method accords with a modified form of
"THL Simplified Phonetic Transcription of Standard Tibetan" developed by David Germano and Nicolas Tournadre. For example, I rendered syllables that end with the vowel "-e" with "-e" (e-acute) to denote /e/ rather than a schwa, e.g., Tséten (Tshe tan) or Géluk (Dge lugs). I also retained the final consonant of Wylie transliteration in terms such as "Zhabdrung" (zhabs drung) and "Jigmé" ('jigs med) in order to accord as much as possible with Tibetan spellings. These slight modifications are aimed to make the pronunciation and readability of Tibetan more accessible to general readers.

On most occasions, the first occurrence of Tibetan proper nouns (e.g., personal names) and important terms appears with the Wylie transliteration following in parentheses. All foreign terms given in parentheses are the Wylie transliteration of Tibetan unless otherwise indicated. Sanskrit terms are marked by (Skt.) according to the International Alphabet of Sanskrit Transliteration (IAST). Chinese (Ch.) terms are given according to pinyin followed by simplified characters. Mongolian terms (Mong.) follow Christopher Atwood's transcriptions as given in his Encyclopedia of Mongolia and the Mongol Empire (2004). Proper nouns are listed in the index according to the phonetics followed by Wylie transliterations. Throughout the main body of the text, Tibetan terms are transcribed phonetically; however, Wylie transliteration is used in notes and sources. When citing sources, I retain previously published renderings of Tibetan names and terms, e.g., Arjia Rinpoche. Unless otherwise noted, all translations found in this book are my own. 
